\title{
Central Leptin Regulation of Obesity and Fertility
}

\author{
Qingchun Tong • Yong Xu
}

Published online: 16 August 2012

(C) Springer Science+Business Media, LLC 2012

\begin{abstract}
The current obesity epidemic and lack of efficient therapeutics demand a clear understanding of the mechanism underlying body weight regulation. The cloning of leptin, a key body weight regulating adipokine released in proportion to the adipose tissue mass, has revolutionized our understanding of the mechanism by which body weight is controlled. It is now well established that the brain, especially the hypothalamus, maintains body weight homeostasis by effectively adjusting food intake and energy expenditure in response to changes in levels of various nutritional status indicators, including leptin. In addition, one major defect in physiology associated with obesity is reduced fertility. Defects in leptin action result in both obesity and infertility, suggesting that leptin may serve as a link between nutrition supply and reproduction. This review reports recent research advance in neural pathways underlying leptin action on body weight and fertility, and discusses the remaining outstanding challenges.
\end{abstract}

Keywords Leptin · Obesity · Reproduction ·

Neurotransmitter · Neuropeptide · Hypothalamus ·

Fertility $\cdot$ Regulation

Q. Tong $(\bowtie)$

The Brown Foundation Institute of Molecular Medicine,

The University of Texas Health Science Center at Houston, 1825 Pressler Street,

Houston, TX 77030, USA

e-mail: qingchun.tong@uth.tmc.edu

Y. Xu

Children's Nutrition Research Center, Department of Pediatrics,

Baylor College of Medicine,

One Baylor Plaza,

Houston, TX 77030, USA

e-mail: yongx@bcm.edu

\section{Introduction}

The last decades have witnessed an alarming obesity epidemic and it is projected that, by year 2030, nearly half of Americans will be obese [1]. Obesity induces an array of metabolic syndromes including type II diabetes mellitus, hypertension, stroke, coronary heart disease as well as compromised reproductive ability [2]. As a result, the economic cost imposed by obesity has become a substantial burden to society, which signifies an urgent need for efficient therapeutics to prevent and treat obesity $[1,3]$. Body weight homeostasis is achieved by complex interactions between the brain and peripheral tissues, and is maintained by balanced energy intake (food intake) and energy expenditure [4]. Obesity develops when energy intake exceeds energy expenditure. One key component of the interaction is leptin, an adipokine indicating energy storage and secreted in proportion to the adipose tissue mass. Leptin mainly acts on brain neurons to inhibit feeding and increase energy expenditure. Recent research aided by mouse genetics has gained substantial progress in understanding neural pathways mediating leptin action. In addition, emerging studies demonstrate that leptin, a signal for energy reserve, also directly regulates reproduction. As diagrammed in Fig. 1, this review briefs recent advance in brain mechanisms underlying leptin action on body weight homeostasis and reproduction.

\section{Leptin and its Receptors}

Prior to the cloning of leptin, the mechanism of body weight regulation was largely unknown. Nonetheless, studies based on crude lesion approaches identified the hypothalamus as a key brain region responsible for body weight homeostasis. Fine lesion studies also established particular subregions within the hypothalamus as either satiety or hunger centers. However, these studies failed to provide an understanding at 
Fig. 1 This diagram shows major leptin action sites in the brain. Neuronal identify of each subsets of leptin-receptor expressing neurons is color coded

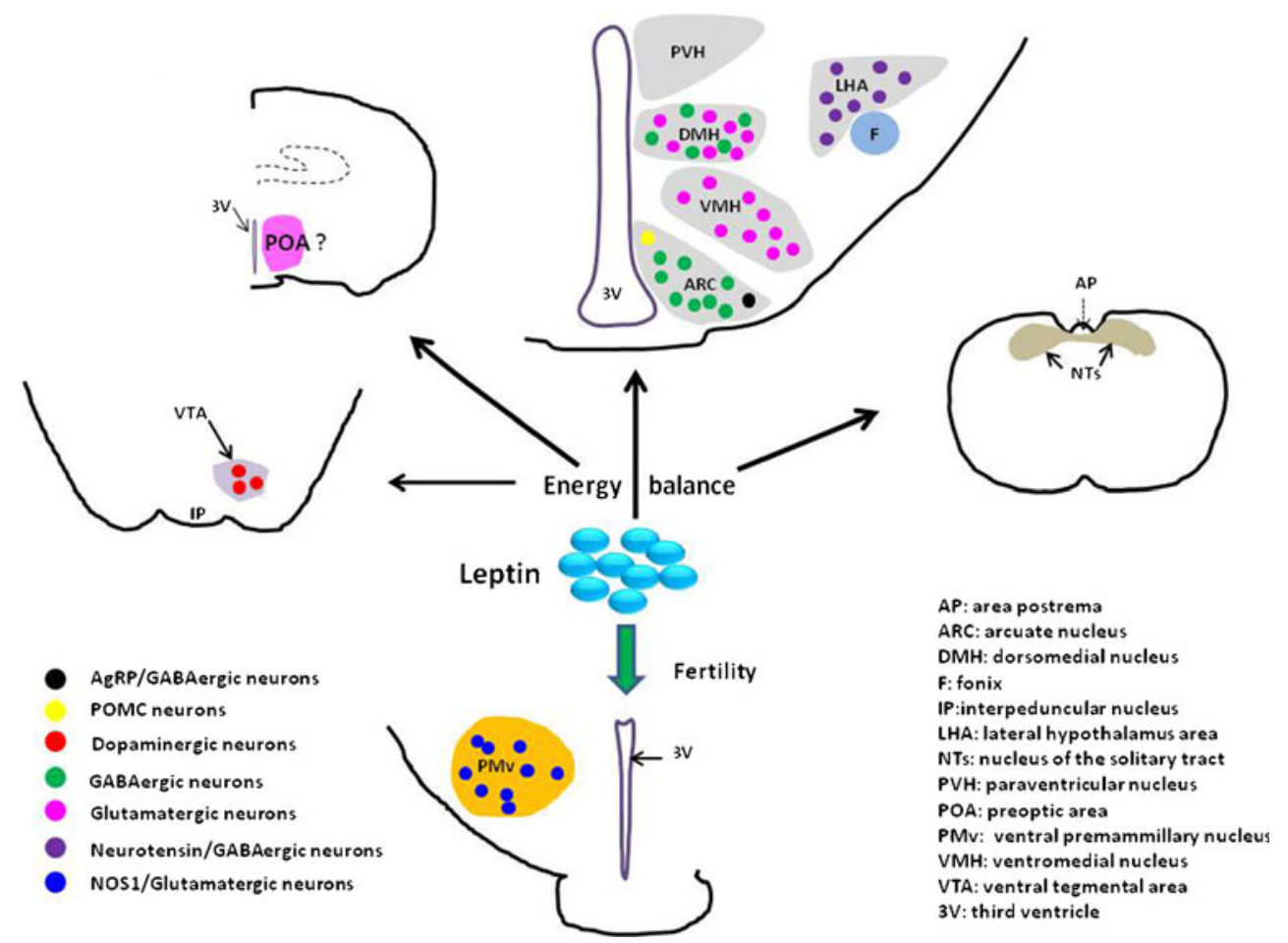

the molecular level. In 1994, the cloning of leptin, a $16 \mathrm{KD}$ protein secreted from adipocytes, has revolutionized our understanding of body weight regulation and provided a molecular tool for studies on body weight homeostasis. It is now well established that leptin is a key regulator of body weight. Leptin, secreted in approximate proportion to the adipose tissue mass, serves as an indicator of body energy reserve, which normally is fat tissue. Increased leptin levels (increased body weight) curtail food intake and stimulate energy expenditure. On the contrary, reduced leptin levels (reduced body weight) stimulate food intake and reduce energy expenditure. The importance of leptin is manifested by mice with deficiency in leptin $(o b / o b)$ exhibit severe obesity, hyperphagia, reduced energy expenditure, diabetes as well as loss of reproduction [5]. Consistently, a similar array of abnormalities are also observed in subjects with inactivation of leptin [6], demonstrating that mice and humans share a common leptin pathway. Importantly, obesity and reproduction defects by leptin deficiency can be rescued by pharmacological administration of leptin, demonstrating the reversibility of leptin function.

Leptin action is mediated by leptin receptors. Currently, there are six isoforms of leptin receptors, which are produced by alternative splicing from a single gene. The function of leptin is mainly mediated by the B isoform of leptin receptors (denoted as LepRb) since a similar phenotype to leptin deficiency was observed in mice $(d b / d b)$ and humans with LepRb inactivation [7-9]. Despite strong evidence showing LepRb expression in other sites, the brain is the major site that mediates the function of leptin since brain- specific deletion of LepRb largely recapitulates phenotypes with whole body LepRb deletion [10]. Reciprocally, abnormalities of the $d b / d b$ mouse are markedly improved by transgenic replacement of central LepRb [11]. Consistent with this, liver-specific deletion of LepRb produces little effects [10].

\section{Leptin Receptor-Expressing Neurons and their Functions in Mediating Leptin Action on Body Weight}

Within the brain, the hypothalamus exhibits the most abundant expression of LepRb [12]. Outside the hypothalamus, LepRb is only expressed in scattered neurons in the cortex, hippocampus, periaqueductal grey, dorsal raphe, the hindbrain and other sites $[13,14]$. Within the hypothalamus, the arcuate nucleus (Arc) shows the highest density of LepRb expression while the ventral premammillary nucleus (PMv), ventromedial hypothalamus (VMH), the dorsal medial hypothalamus (DMH) and preoptic area (POA) also show prominent expression $[13,14]$. Consistent with LepRb expression in the brain, nuclear p-STAT3 expression induced by leptin activation is abundantly expressed in the hypothalamus, and to a lesser degree in other brain regions such as hindbrain and midbrain areas. Collectively, the hypothalamus is the major site in the brain that mediates leptin action on energy balance regulation.

Given the highest degree of expression in LepR expression and p-STAT3 expression in response to leptin action in the Arc, and closest vicinity of these neurons to the median 
eminence (ME), the Arc LepRb neurons have long been postulated to be the major mediator of leptin action. Indeed, specific re-expression of LepRb in the Arc dramatically rescues obesity phenotype of $d b / d b$ mice [15].The most recognized function of Arc neurons in mediating leptin action is that mediated by proopiomelanocortin (POMC) and agouti-related peptide (AgRP) neurons, two key groups of neurons of the melanocortin system. Indeed, direct leptin action on POMC and AgRP neurons has been revealed by the obesity phenotypes caused by specific deletion of LepRb in POMC and AgRP neurons [16, 17]. Interestingly, simultaneous deletion of LepRb in POMC and VMH or AgRP neurons produces an additive effect on obesity over individual group [17, 18], suggesting that neural pathways involving these neurons in mediating leptin action on body weight are largely independent.

Given the well-established role of POMC and AgRP neurons in feeding and body weight regulation, the effect of LepRb deletion in POMC and/or AgRP neurons on body weight is surprisingly small, relative to that produced by LepRb deficiency $[16,17]$. One possibility is that LepRb expression in these neurons is important; but specific deletion of LepRb in these neurons in early embryonic stages induces developmental compensation from redundant pathways. This possibility appears not to be the case for POMC neurons since re-expression of LepRb selectively in POMC neurons, under which condition no developmental compensation will occur, produces little effects on body weight while largely restores euglycemia in $d b / d b$ mice $[19,20]$. However, it could be the case for AgRP neurons since lesion of these neurons in neonatal stages produces little effects while that in adulthood leads to starvation [21]. Thus, further studies with inducible deletion of LepRb in AgRP neurons in adulthood are required to assess direct action of AgRP neurons in mediating leptin action on body weight. The other possibility is that there exist other unidentified groups of neurons in the Arc, which play more important roles in mediating leptin action. The mild role of LepRb in POMC and AgRP neurons is simply due to the fact that these neurons only account for a fraction of total LepRbexpressing neurons in the Arc. Consistent with a minor role of POMC neurons in mediating leptin action, only a fraction of POMC neurons express LepRb [22]. The existence of unidentified LepRb-expressing neurons in the Arc is supported by recent data that leptin activation of POMC neurons is indirectly mediated by reducing GABA release to these neurons [23••]. Importantly, AgRP neurons are not a significant part of the GABAergic neuron since disruption of GABA release from AgRP neurons produces little effects on leptin activation on POMC neurons. Given the fact that Arc neurons are mainly GABAergic neurons and LepRb is mostly abundantly expressed in the Arc, the GABAergic neurons that directly respond to leptin are most likely located in the Arc. Future efforts should be directed to understand the role of non-POMC, non-AgRP neurons in the Arc in mediating leptin action.

Earlier lesion studies suggest the VMH as a satiety center in the brain. Consistently, defects in VMH development by deletion of steroidogenic factor 1 (SF1), a transcription factor required for $\mathrm{VMH}$ development, lead to massive obesity and hyperphagia. Further, specific deletion of SF1 in adult VMH also causes obesity [24], suggesting a role for SF1 in maintaining the role of VMH neurons in obesity regulation. Consistent with prominent expression of LepRb in the VMH, the VMH shows prominent p-STAT3 expression in response to leptin, suggesting an important role for VMH neurons in mediating leptin action. Indeed, specific deletion of LepRb in the VMH causes obesity associated with hyperphagia [18]. However, compared to those of $\mathrm{VMH} / \mathrm{SF} 1$ lesion on obesity, the effect of LepRb deletion in the VMH is mild. These results suggest that the VMH only mediates part of leptin action on body weight and that the VMH mediates the action of other important factors for body weight homeostasis.

Both DMH and lateral hypothalamus express abundant LepRb and shows robust p-STAT3 expression in response to leptin action [13], suggesting an important function for LepRb-expressing neurons in these regions in mediating leptin action. Despite this, the specific role of LepRb in these regions remains elusive due to lack of means to genetically target these regions, i.e., mouse strains with specific Cre expression in these regions. Nonetheless, accumulating evidence suggests a role for these neurons in mediating body weight homeostasis. DMH LepRb neurons receive prominent inputs from preoptic neurons and send strong projections to the brown adipose tissue (BAT) [25], indicating a role for these neurons in energy expenditure. Consistently, a role for these neurons in mediating leptin action on thermogenesis in diet-induced obesity mice has been demonstrated [26•]. These data suggest a functional role for these $\mathrm{DMH}$ LepRb-expressing neurons in energy expenditure regulation. Interestingly, in the lateral hypothalamus, LepRb-expressing neurons express neurotensin and are largely GABAergic; these neurons are neither orexin nor $\mathrm{MCH}$ positive, but instead lie upstream of orexin and $\mathrm{MCH}$ neurons, providing GABAergic innervations [27•]. Importantly, the LepRb-expressing neurons in the lateral hypothalamus also project to ventral tegmental area (VTA) dopaminergic neurons and this projection is important for feeding regulation by modulating dopamine release.

Recent studies also demonstrated an important role for those LepRb-expressing neurons that are located outside the hypothalamus. LepRb is expressed in a small subset of VTA neurons. Although it remains unclear how leptin directly modulates dopamine action, convergent evidence suggests that dopamine may mediate leptin action on locomotion and 
hedonic aspects of food consumption [28]. LepRb is also expressed a subset of hindbrain neurons, especially in the nucleus of solitary tract (NTS) area. Peripheral co-administration of leptin and cholecystokinin (CCK), a gut derived hormone, causes a synergistic effect in reducing feeding [29], suggesting the existence of a common subset of neurons that express both LepRb and CCK receptors, which are likely located in the hindbrain/NTS area. Consistently, specific deletion of LepRb in the NTS area leads to obesity, demonstrating a role for NTS LepRb-expressing neurons in body weight regulation [30]. Surprisingly, NTS deletion of LepRb causes no alternations in food intake.

\section{Neurotransmitters Mediating Leptin Action}

One key step in understanding leptin neural pathways is to reveal the neurotransmitters that mediate the function of important LepRb-expressing neurons. In the Arc, it is well established that $\alpha$-MSH released from POMC, and AgRP and NPY released from AgRP neurons mediate leptin action. Compelling pharmacological data demonstrate that AgRP and NPY, when administered in the brain, produce powerful orexigenic effects, while $\alpha$-MSH and its mimetic, MTII, produce anorexigenic effects [31]. Electrophysiological data demonstrate that leptin activates POMC neurons while inhibiting AgRP neurons [32]. In further corroboration with this, fasting induces robust up-regulation of AgRP and NPY, and down-regulation of POMC, which coincides with decreased levels of leptin [33], suggesting that the underlying mechanism for fasting-induced hyperphagia is inhibition of POMC neurons and "dis-inhibition" of AgRP neurons as a result of reduced leptin levels. Genetically, genetic knockout of POMC or over-expression of AgRP (agouti mice) leads to severe obesity [34], demonstrating a powerful role for the melanocortin system in body weight regulation. In addition, $\beta$-endorphin and adrenocorticotropin (ACTH), both of which are encoded by the same POMC gene, cocaine- and amphetamine-regulated transcript peptide (CART), galanin-like peptide (GALP) and kisspeptin appear also to be released from LepRb neurons in the Arc; however, their function in mediating leptin function remains to be established. In the VMH, expression levels of brainderived neurotrophic factor (BDNF) responds to nutritional status and deletion of VMH BDNF leads to obesity and hyperphagia $[35,36]$, suggesting that BDNF mediates the action of VMH neurons in the regulation of energy balance. In addition, recent results indicate that pituitary adenylate cyclase activating polypeptide (PACAP) is abundantly expressed in the $\mathrm{VMH}$ and its expression levels respond to nutritional status, suggesting a potential role for PACAP in body weight regulation [37]. NPY expression in the DMH appears to regulate body weight [38]; however, it remains to ascertain the extent to which DMH NPY mediates leptin action. No neuropeptide has yet been implicated in directly mediating leptin action in the lateral hypothalamus as well as other brain regions.

Given the importance of fast-acting neurotransmission in general, fast-acting neurotransmitters released from LepRb neurons are probably the major mediators for leptin action. Notably, key hypothalamic regions with abundant LepRb expression are mainly glutamatergic or GABAergic [39]. The Arc expresses abundant vesicular GABA transporter (VGAT), but little vesicular glutamate transporter 2 (VGLUT2), suggesting the majority of Arc neurons are largely GABAergic. The VMH and PMv express abundant VGLUT2, but little VGAT, suggesting that neurons in these regions are largely glutamatergic. The DMH and POA express both VGLUT2 and VGAT, suggesting that neurons in these brain sites are composed of both glutamatergic and GABAergic neurons (see the diagram in Fig. 1).

Based on the animal model with LepRb deletion in GABAergic neurons, a recent study revealed that LepRb in GABAergic neurons mediate a major part of leptin role on body weight regulation [23••], suggesting a major role for GABA release in mediating leptin action. In contrast, specific disruption of GABA release from LepRb neurons leads to mild obesity associated with hyperphagia and reduced energy expenditure $[40 \bullet \bullet]$. These results may lead to speculations that other neurotransmitters released from LepRb-expressing neurons play an important role or that disruption of GABA release from different subsets of LepRb-expression causes opposite effects, i.e., body weight-reducing effect from leptin-inhibited neurons and body weight-increasing effect from leptin-excited neurons. Consistent with this idea, disruption of GABA release from AgRP neurons, well established leptin-inhibited neurons, leads to reduced body weight associated with increased energy expenditure [41]. Further studies with disruption of GABA release from each distinct subset of LepR-expressing neurons will provide more insights on GABAergic action in mediating leptin function.

Surprisingly, despite its strong expression in the VMH, deletion of VGLUT2 in the VMH leads to normal body weight on chow and only slightly increased body weight on high fat diet, suggesting a role for other neurotransmitters in mediating body weight action of VMH neurons [42]. Clearly, further studies are required to examine the role of glutamate release from the PVH and PMv, and glutamate and GABA release from the $\mathrm{DMH}$ and POA.

\section{Leptin Neural Pathway for Reproduction}

It is well established that nutrition and reproduction are tightly coordinated. On one hand, a minimum amount of 
stored energy is required for normal pubertal development and to maintain the tone of the reproductive system [43, 44]. When survival is threatened by unavailability of food or increased energy demands, males and females of most species divert energy away from reproduction-related processes. These include pubertal development, the production of reproductive hormones and gametes, and the maintenance of pregnancy and lactation. On the other hand, excess energy also has a negative impact on the reproductive physiology. For example, elevated adiposity in women aggravates polycystic ovarian syndrome and ovulatory dysfunctions and may induce hypothalamic hypogonadism [45, 46]. Moreover, the increasing rates of childhood obesity have been associated with the advance in the timing of pubertal maturation and its deleterious consequences [47-50]. Collectively, these findings predict that factors must exist to regulate energy homeostasis and reproductive functions in a coordinated fashion.

The adipocyte-derived hormone leptin is certainly one suitable signal that provides the fundamental link between energy balance and reproduction. For example, obesity seen in mice lacking leptin $(o b / o b)$ or LepRb $(d b / d b)$ is accompanied by infertility [51-53]. These mice also exhibit low luteinizing hormone (LH) levels and incomplete development of reproductive organs and do not undergo puberty. Leptin administration to $o b / o b$ mice can completely rescue all these phenotypes [54-56]. Further, humans with leptin deficiency develop similar reproductive phenotypes as seen in $o b / o b$ mice [6]. In these patients, leptin replacement induces an increase in the levels of gonadotropins and sex steroids as well as enlargement of the gonads and normal pubertal development $[57,58]$. Leptin also overrides the fasting-induced suppression of LH secretion and fertility [59-62]. In anorectic females and in athletes with extreme decreases in body adiposity, leptin can increase levels of LH [63] and restore the menstrual cycle [64]. Clearly, leptin serves as a key circulating molecule that mirrors the internal energy storage and therefore produces a permissive signal for normal reproductive functions. In conditions that leptin signals are impaired due to lack of energy store or genetic mutations, reproductive functions are compromised as a defending mechanism to reserve energy and increase survival.

Re-expression of LepRb in the brain of LepRb-null mice restores fertility completely in males and partially in females $[65,66]$. These indicate that leptin acts primarily via LepRb in the brain to regulate reproduction. An interesting question is whether leptin-mediated regulations on energy balance and on reproduction are mediated by the same or overlapping neural circuits. While many LepRb-expressing neural populations have been identified as critical regulators of body weight (as discussed above), our efforts to identify LepRb sites important for reproduction have just begun.
Among many sites that deserve investigation, the most studied LepRb site in the context of reproduction is perhaps the PMv. The PMv expresses abundant leptin receptors and projects directly to gonadotropin releasing hormone (GnRH) neurons $[67,68]$. Elias and coworkers reported that adult female rats with bilateral lesions of the PMv are unresponsive to leptin's effect to induce LH secretion [69]. They further demonstrated that while exogenous leptin can rescue development of puberty in $o b / o b$ mice with intact PMv, bilateral lesions of the region blunted the effects of leptin [70••]. Importantly, unilateral re-expression of endogenous LepRb in PMv neurons was sufficient to induce puberty and partially improve fertility in female $d b / d b$ mice $[70 \bullet \cdot$. The re-expression of LepRb in the PMv also normalized the increased hypothalamic GnRH content characteristic of leptin-signaling deficiency $[70 \bullet \cdot]$. These data suggest that LepRb expressed in the PMv is sufficient to mediate leptin's action at the onset of puberty.

The role of LepRb in the PMv was further supported by a recent report by Myers and coworkers [71••]. They first identified that about $20 \%$ of LepRb-positive neurons express nitric oxide synthase 1 (NOS1), an enzyme responsible for production of nitric oxide in neurons. Interestingly, these LepRb-positive NOS1 neurons are predominantly in the PMv, with a few of them located in the DMH and Arc. Notably, the LepRb-positive NOS1 neurons in the Arc are distinct from POMC and AgRP neurons. Importantly, female mice lacking LepRb selectively in NOS1 neurons showed delayed puberty, although their fertility did not appear to be affected. Nevertheless, Myers observations indicate that LepRb in the PMv (as well as in the DMH and Arc) is required for the normal development of puberty. Together with Elias's findings, these results identified the PMv as the key site where leptin signals are both required and sufficient to regulate pubertal development. Importantly, mice lacking LepRb in NOS1 neurons also developed severe obesity $[71 \bullet \cdot$. Thus, the PMv may serve a critical node where the metabolic and reproductive signals are coordinated.

It is noted, however, that LepRb in the PMv is neither sufficient $[70 \bullet \bullet$ nor required $[71 \bullet \bullet$ to mediate leptin's effects on fertility. This suggests that leptin acts on anatomically dissociated LepRb populations to regulate pubertal development and fertility. POMC neurons may be the direct target of leptin and insulin actions important for fertility. Hill and coworkers reported that female mice lacking both leptin and insulin receptors in POMC neurons exhibit lengthened reproductive cycles, follicular arrest, hyperandrogenemia, and are sub-fertile [72•]. While hypothalamic GnRH gene expression was normal, LH levels were significantly increased in females. Histological examination of their ovaries showed that double knockout females exhibited more degenerating follicles. Serum testosterone 
levels were significantly elevated in females, accompanied by a significant elevation in the expression of ovarian $3 \beta-$ HSD I gene, which produces androstenedione. Collectively, these results suggest that the absence of leptin and insulin signaling in POMC neurons may reduce the inhibitory tone on GnRH neurons and cause basal LH levels to increase, disrupting reproductive function. Interestingly, such reproductive phenotypes were not observed in mice lacking either receptor alone in POMC neurons, suggesting that signals initiated by leptin and insulin in POMC neurons are functionally redundant in the context of fertility.

Another possible site that mediates leptin actions on reproduction is Kiss 1 neurons in the Arc. About $15 \%$ Kiss1 neurons in the Arc respond to leptin with activation of the STAT3 pathway [73]. Leptin-deficient $o b / o b$ male mice show decreased expression of Kiss 1 in the Arc, which is increased by leptin treatment [74]. Hypothalamic Kiss 1 mRNA levels are decreased in male rats made diabetic by administration of streptozotocin [75]. Intracerebroventricular administration of leptin normalizes Kiss 1 gene expression and the levels of LH and androgens. However, genetic deletion of LepRb selectively from hypothalamic Kiss1 neurons in mice had no effect on puberty or fertility $[70 \bullet \cdot$. These results may indicate that direct leptin signaling in Kiss1 neurons is not required for these processes. Alternatively, the lack of reproductive phenotypes in mice with embryonic deletion of LepRb from Kiss1 neurons may be due to the existence of compensatory pathways. Indeed, recent studies showed that embryonic ablation of neurons expressing Kiss1 or its receptor (GPR54) did not affect puberty and fertility, while acute ablation of Kiss1 neurons from adult mice inhibited fertility [76]. Thus, the requirement of leptin signaling on Kiss1 neurons for normal pubertal development has not been fully excluded and deserves further investigation.

\section{Conclusions}

In summary, exciting progress has been made in our understanding of the neural pathway that mediates leptin action. Given the demonstrated roles of leptin receptor-expressing neurons in body weight in the Arc, VHM, LH, VTA and the hindbrain, it appears that leptin action on body weight is mediated by a widely distributed neural network. It remains unknown whether LepRb-expressing neurons in the $\mathrm{DMH}$, POA and PMv also mediate leptin action on body weight. However, based on recent observations that LepRb in both GABAergic neurons and NOS1 expressing neurons mediates predominantly leptin action on body weight $[23 \bullet \bullet, 71 \bullet \bullet]$, a small subset of GABAergic LepRb neurons located in the Arc may play a major part in mediating leptin action. Further studies are required to identify this subset of neurons. For fertility regulation, it is unknown to what extent fertility is directly regulated by leptin action and indirectly associated by the obesity caused by defects in leptin action. Previous studies suggest that mice with impaired LepRb $\rightarrow$ STAT3 signaling exhibit the same degree of obesity as in $o b / o b$ mice, but maintain fertility, suggesting a direct role for leptin action in fertility [5]. Interestingly, a recent study found that while AgRP neurons are not necessary for fertility, acute lesion of these neurons can rescue the fertility in leptin-deficient $o b / o b$ mice $[77 \cdot \bullet]$. Since the rescuing effect in fertility is accompanied by rescued body weight, this result argues that infertility in $o b / o b$ mice may also be a secondary consequence of obesity. Further studies are warranted to dissect leptin-direct and indirect pathways for fertility regulation.

It is well established that leptin action in the hypothalamus is critical for body weight homeostasis. However, the vast majority of obesity is associated with high leptin levels, indicative of leptin resistance. Thus, strategies aiming at reversing leptin resistance, activating post-leptin resistance signal step and bypassing leptin resistance represent promising therapeutics for obesity treatment. A large body of evidence suggests multiple molecules and intracellular leptin signaling pathways as leptin resistance sites [78]. Neurotransmitter release and its action on postsynaptic neurons represent major post-leptin resistance steps. With the advent of new technologies, more neurotransmitters and new function of existing neurotransmitters will be identified, which will lead to delineation of brain mechanisms governing energy balance and provide novel targets for specific and effective drugs to reverse and prevent the current devastating obesity epidemic and its associated infertility.

Acknowledgments The authors acknowledge grant support from NIH (R01 DK092605 to Q.T. and R01 DK093587 to Y.X.). Also, Y. $\mathrm{Xu}$ has received grant support from USDA, American Diabetes Association, Klarman Family Foundation, Naman Family Fund for Basic Research, and Curtis Hankamer Basic Research Fund.

Disclosure No potential conflicts of interest relevant to this article were reported.

\section{References}

Papers of particular interest, published recently, have been highlighted as:

- Of importance,

•• Of major importance

1. Wang YC, McPherson K, Marsh T, Gortmaker SL, Brown M. Health and economic burden of the projected obesity trends in the USA and the UK. Lancet. 2011;378(9793):815-25.

2. Patel SB, Reams GP, Spear RM, Freeman RH, Villarreal D. Leptin: linking obesity, the metabolic syndrome, and cardiovascular disease. Curr Hypertens Rep. 2008;10(2):131-7. 
3. Swinburn BA, Sacks G, Hall KD, et al. The global obesity pandemic: shaped by global drivers and local environments. Lancet. 2011;378(9793):804-14.

4. Flier JS. Obesity wars: molecular progress confronts an expanding epidemic. Cell. 2004;116(2):337-50.

5. Bates SH, Myers Jr MG. The role of leptin receptor signaling in feeding and neuroendocrine function. Trends Endocrinol Metab. 2003;14(10):447-52.

6. Montague CT, Farooqi IS, Whitehead JP, et al. Congenital leptin deficiency is associated with severe early-onset obesity in humans. Nature. 1997;387(6636):903-8.

7. Lee GH, Proenca R, Montez JM, et al. Abnormal splicing of the leptin receptor in diabetic mice. Nature. 1996;379 (6566):632-5.

8. Chen $\mathrm{H}$, Charlat $\mathrm{O}$, Tartaglia LA, et al. Evidence that the diabetes gene encodes the leptin receptor: identification of a mutation in the leptin receptor gene in db/db mice. Cell. 1996;84(3):491-5.

9. Clement K, Vaisse C, Lahlou N, et al. A mutation in the human leptin receptor gene causes obesity and pituitary dysfunction. Nature. 1998;392(6674):398-401.

10. Cohen P, Zhao C, Cai X, et al. Selective deletion of leptin receptor in neurons leads to obesity. J Clin Invest. 2001;108(8):1113-21.

11. de Luca C, Kowalski TJ, Zhang Y, et al. Complete rescue of obesity, diabetes, and infertility in $\mathrm{db} / \mathrm{db}$ mice by neuron-specific LEPR-B transgenes. J Clin Invest. 2005;115(12):3484-93.

12. Schwartz MW, Seeley RJ, Campfield LA, Burn P, Baskin DG. Identification of targets of leptin action in rat hypothalamus. J Clin Invest. 1996;98(5):1101-6.

13. Scott MM, Lachey JL, Sternson SM, et al. Leptin targets in the mouse brain. J Comp Neurol. 2009;514(5):518-32.

14. Patterson CM, Leshan RL, Jones JC, Myers Jr MG. Molecular mapping of mouse brain regions innervated by leptin receptorexpressing cells. Brain Res. 2011;1378:18-28.

15. Coppari R, Ichinose M, Lee CE, et al. The hypothalamic arcuate nucleus: a key site for mediating leptin's effects on glucose homeostasis and locomotor activity. Cell Metab. 2005;1(1):63-72.

16. Balthasar N, Coppari R, McMinn J, et al. Leptin receptor signaling in POMC neurons is required for normal body weight homeostasis. Neuron. 2004;42(6):983-91.

17. van de Wall E, Leshan $\mathrm{R}, \mathrm{Xu} \mathrm{AW}$, et al. Collective and individual functions of leptin receptor modulated neurons controlling metabolism and ingestion. Endocrinology. 2008;149(4):1773-85.

18. Dhillon H, Zigman JM, Ye C, et al. Leptin directly activates SF1 neurons in the $\mathrm{VMH}$, and this action by leptin is required for normal body-weight homeostasis. Neuron. 2006;49(2):191-203.

19. Huo L, Gamber K, Greeley S, et al. Leptin-dependent control of glucose balance and locomotor activity by POMC neurons. Cell Metab. 2009;9(6):537-47.

20. Berglund ED, Vianna CR, Donato Jr J, et al. Direct leptin action on POMC neurons regulates glucose homeostasis and hepatic insulin sensitivity in mice. J Clin Invest. 2012;122(3):1000-9.

21. Luquet S, Perez FA, Hnasko TS, Palmiter RD. NPY/AgRP neurons are essential for feeding in adult mice but can be ablated in neonates. Science. 2005;310(5748):683-5.

22. Williams KW, Margatho LO, Lee CE, et al. Segregation of acute leptin and insulin effects in distinct populations of arcuate proopiomelanocortin neurons. J Neurosci. 2010;30(7):2472-9.

23. •• Vong L, Ye C, Yang Z, Choi B, Chua Jr S, Lowell BB. Leptin action on GABAergic neurons prevents obesity and reduces inhibitory tone to POMC neurons. Neuron. 2011;71(1):142-54. This study generated mice with LepR deletion specifically in GABAergic neurons and glutamatergic neurons. It was found that deletion of LepR in GABAergic produces massive obesity while that in glutamatergic neurons produces only mild obesity, therefore suggesting that GABAergic neurons mediate predominantly leptin action on body weight.
24. Kim KW, Zhao L, Donato Jr J, et al. Steroidogenic factor 1 directs programs regulating diet-induced thermogenesis and leptin action in the ventral medial hypothalamic nucleus. Proc Natl Acad Sci USA. 2011;108(26):10673-8.

25. Zhang Y, Kerman IA, Laque A, et al. Leptin-receptor-expressing neurons in the dorsomedial hypothalamus and median preoptic area regulate sympathetic brown adipose tissue circuits. J Neurosci. 2011;31(5):1873-84.

26. - Enriori PJ, Sinnayah P, Simonds SE, Garcia Rudaz C, Cowley MA. Leptin action in the dorsomedial hypothalamus increases sympathetic tone to brown adipose tissue in spite of systemic leptin resistance. J Neurosci. 2011;31(34):12189-97. This study demonstrated a selective leptin resistance. During lepin resistance state, it was found that leptin action in the DMH remains as sensitive as normal mice. Although leptin action on feeding is blunted, leptin action in inducing thermogenesis in the brown fat is as sensitive as in control lean mice. This result will help to explain hypertension associated with the obesity.

27. - Leinninger GM, Opland DM, Jo YH, et al. Leptin action via neurotensin neurons controls orexin, the mesolimbic dopamine system and energy balance. Cell Metab. 2011;14(3):313-23. The authors identified that neurotensin neurons in the LH express leptin receptor and send prejections to the VTA area. Specific deletion of LepR in neurontensin neurons leads to obesity and leads to blunted effects of lepin action in LH on feeding. These neurotensin neurons are identified to be GABAergic and appear to be upstream of orexin and MCH neurons. Thus this study identified a novel leptin pathway from LH to VTA to modulate body weight.

28. Palmiter RD. Is dopamine a physiologically relevant mediator of feeding behavior? Trends Neurosci. 2007;30(8):375-81.

29. Barrachina MD, Martinez V, Wang L, Wei JY, Tache Y. Synergistic interaction between leptin and cholecystokinin to reduce shortterm food intake in lean mice. Proc Natl Acad Sci USA. 1997;94 (19):10455-60.

30. Scott MM, Williams KW, Rossi J, Lee CE, Elmquist JK. Leptin receptor expression in hindbrain Glp-1 neurons regulates food intake and energy balance in mice. J Clin Invest. 2011;121 (6):2413-21.

31. Kalra SP, Kalra PS. Neuroendocrine control of energy homeostasis: update on new insights. Prog Brain Res. 2010;181:17-33.

32. Cowley MA, Smart JL, Rubinstein M, et al. Leptin activates anorexigenic POMC neurons through a neural network in the arcuate nucleus. Nature. 2001;411(6836):480-4.

33. Takahashi KA, Cone RD. Fasting induces a large, leptin-dependent increase in the intrinsic action potential frequency of orexigenic arcuate nucleus neuropeptide $\mathrm{Y} /$ Agouti-related protein neurons. Endocrinology. 2005;146(3):1043-7.

34. Ollmann MM, Wilson BD, Yang YK, et al. Antagonism of central melanocortin receptors in vitro and in vivo by agouti-related protein. Science. 1997;278(5335):135-8.

35. Xu B, Goulding EH, Zang K, et al. Brain-derived neurotrophic factor regulates energy balance downstream of melanocortin-4 receptor. Nat Neurosci. 2003;6(7):736-42.

36. Unger TJ, Calderon GA, Bradley LC, Sena-Esteves M, Rios M. Selective deletion of Bdnf in the ventromedial and dorsomedial hypothalamus of adult mice results in hyperphagic behavior and obesity. J Neurosci. 2007;27(52):14265-74.

37. Hawke Z, Ivanov TR, Bechtold DA, Dhillon H, Lowell BB, Luckman SM. PACAP neurons in the hypothalamic ventromedial nucleus are targets of central leptin signaling. J Neurosci. 2009;29 (47):14828-35.

38. Chao PT, Yang L, Aja S, Moran TH, Bi S. Knockdown of NPY expression in the dorsomedial hypothalamus promotes development of brown adipocytes and prevents diet-induced obesity. Cell Metab. 2011;13(5):573-83. 
39. Xu Y, Tong Q. Expanding neurotransmitters in the hypothalamic neurocircuitry for energy balance regulation. Protein Cell. 2011;2 (10):800-13.

40. • Xu Y, O'Brien 3rd WG, Lee CC, Myers Jr MG, Tong Q. Role of GABA release from leptin receptor-expressing neurons in body weight regulation. Endocrinology. 2012;153(5):2223-33. The authors generated mice with disruption of GABA release from LepR neurons to investigate the role of GABA release in mediating leptin action on body weight. These mice showed mild obesity associated with hyperphagia and reduced energy expenditure, suggesting a role for GABA in mediating leptin action on body weight.

41. Tong Q, Ye CP, Jones JE, Elmquist JK, Lowell BB. Synaptic release of GABA by AgRP neurons is required for normal regulation of energy balance. Nat Neurosci. 2008;11(9):998-1000.

42. Tong Q, Ye C, McCrimmon RJ, et al. Synaptic glutamate release by ventromedial hypothalamic neurons is part of the neurocircuitry that prevents hypoglycemia. Cell Metab. 2007;5 (5):383-93.

43. Kennedy GC. Interactions between feeding behavior and hormones during growth. Ann N Y Acad Sci. 1969;157(2):1049-61.

44. Frisch RE, McArthur JW. Menstrual cycles: fatness as a determinant of minimum weight for height necessary for their maintenance or onset. Science. 1974;185(4155):949-51.

45. Rittmaster RS, Deshwal N, Lehman L. The role of adrenal hyperandrogenism, insulin resistance, and obesity in the pathogenesis of polycystic ovarian syndrome. J Clin Endocrinol Metab. 1993;76 (5):1295-300.

46. Bluher S, Mantzoros CS. Leptin in reproduction. Curr Opin Endocrinol Diabetes Obes. 2007;14(6):458-64.

47. Biro FM, Galvez MP, Greenspan LC, et al. Pubertal assessment method and baseline characteristics in a mixed longitudinal study of girls. Pediatrics. 2010;126(3):e583-590.

48. Biro FM, Khoury P, Morrison JA. Influence of obesity on timing of puberty. Int J Androl. 2006;29(1):272-7. discussion 286-290.

49. Freedman DS, Khan LK, Serdula MK, Dietz WH, Srinivasan SR, Berenson GS. The relation of menarcheal age to obesity in childhood and adulthood: the Bogalusa heart study. BMC Pediatr. 2003;3:3.

50. Herman-Giddens ME, Slora EJ, Wasserman RC, et al. Secondary sexual characteristics and menses in young girls seen in office practice: a study from the Pediatric Research in Office Settings network. Pediatrics. 1997;99(4):505-12.

51. Coleman DL. Obese and diabetes: two mutant genes causing diabetes-obesity syndromes in mice. Diabetologia. 1978;14 (3):141-8

52. Zhang Y, Proenca R, Maffei M, Barone M, Leopold L, Friedman JM. Positional cloning of the mouse obese gene and its human homologue. Nature. 1994;372(6505):425-32.

53. Tartaglia LA, Dembski M, Weng X, et al. Identification and expression cloning of a leptin receptor, OB-R. Cell. 1995;83 (7):1263-71.

54. Barash IA, Cheung CC, Weigle DS, et al. Leptin is a metabolic signal to the reproductive system. Endocrinology. 1996;137 (7):3144-7.

55. Chehab FF, Lim ME, Lu R. Correction of the sterility defect in homozygous obese female mice by treatment with the human recombinant leptin. Nat Genet. 1996;12(3):318-20.

56. Mounzih K, Lu R, Chehab FF. Leptin treatment rescues the sterility of genetically obese ob/ob males. Endocrinology. 1997;138 (3):1190-3.

57. Farooqi IS, Jebb SA, Langmack G, et al. Effects of recombinant leptin therapy in a child with congenital leptin deficiency. N Engl J Med. 1999;341(12):879-84.

58. Farooqi IS, Matarese G, Lord GM, et al. Beneficial effects of leptin on obesity, T cell hyporesponsiveness, and neuroendocrine/ metabolic dysfunction of human congenital leptin deficiency. J Clin Invest. 2002;110(8):1093-103.

59. Nagatani S, Guthikonda P, Thompson RC, Tsukamura H, Maeda KI, Foster DL. Evidence for GnRH regulation by leptin: leptin administration prevents reduced pulsatile LH secretion during fasting. Neuroendocrinology. 1998;67(6):370-6.

60. Kohsaka A, Watanobe H H, Kakizaki Y, Habu S, Suda T. A significant role of leptin in the generation of steroid-induced luteinizing hormone and prolactin surges in female rats. Biochem Biophys Res Commun. 1999;254(3):578-81.

61. Gonzalez LC, Pinilla L, Tena-Sempere M, Aguilar E. Leptin(116130) stimulates prolactin and luteinizing hormone secretion in fasted adult male rats. Neuroendocrinology. 1999;70(3):213-20.

62. Nagatani S, Zeng Y, Keisler DH, Foster DL, Jaffe CA. Leptin regulates pulsatile luteinizing hormone and growth hormone secretion in the sheep. Endocrinology. 2000;141(11):3965-75.

63. Licinio J, Negrao AB, Mantzoros C, Kaklamani V, et al. Synchronicity of frequently sampled, 24-h concentrations of circulating leptin, luteinizing hormone, and estradiol in healthy women. Proc Natl Acad Sci USA. 1998;95(5):2541-6.

64. Welt CK, Chan JL, Bullen J, Murphy R, et al. Recombinant human leptin in women with hypothalamic amenorrhea. N Engl J Med. 2004;351(10):987-97.

65. Kowalski TJ, Liu SM, Leibel RL, Chua Jr SC, Chua Jr SC. Transgenic complementation of leptin-receptor deficiency. I. Rescue of the obesity/diabetes phenotype of LEPR-null mice expressing a LEPR-B transgene. Diabetes. 2001;50(2):425-35.

66. de Luca C, Kowalski TJ, Zhang Y, Elmquist JK, et al. Complete rescue of obesity, diabetes, and infertility in $\mathrm{db} / \mathrm{db}$ mice by neuronspecific LEPR-B transgenes. J Clin Invest. 2005;115(12):3484-93.

67. Louis GW, Greenwald-Yarnell M, Phillips R, Coolen LM, Lehman MN, Myers Jr MG. Molecular mapping of the neural pathways linking leptin to the neuroendocrine reproductive axis. Endocrinology. 2011;152(6):2302-10.

68. Leshan RL, Louis GW, Jo YH, Rhodes CJ, Munzberg H, Myers Jr MG. Direct innervation of GnRH neurons by metabolic- and sexual odorant-sensing leptin receptor neurons in the hypothalamic ventral premammillary nucleus. J Neurosci. 2009;29(10):3138-47.

69. Donato Jr J, Silva RJ, Sita LV, et al. The ventral premammillary nucleus links fasting-induced changes in leptin levels and coordinated luteinizing hormone secretion. J Neurosci. 2009;29 (16):5240-50.

70. • Donato Jr J, Cravo RM, Frazao R, et al. Leptin's effect on puberty in mice is relayed by the ventral premammillary nucleus and does not require signaling in Kiss1 neurons. J Clin Invest. 2011;121(1):355-68. The authors found that bilateral lesion of PMv blunted the effects of leptin in resucing fertility of ob/ob mice, and that re-expression of LepR in the PMv of LepR deficient mice improves the fertility, suggesting that LepR in the PMv is both required and necessary for leptin action on fertility.

71. •• Leshan RL, Greenwald-Yarnell M, Patterson CM, Gonzalez IE, Myers Jr MG. Leptin action through hypothalamic nitric oxide synthase-1-expressing neurons controls energy balance. Nat Med. 2012. The authors deleted LepR in neurons expressing NO synthase 1 (NOS1) and found that LepR in NOS1 neurons mediates predominant action of leptin on body weight, but not for fertility. Since LepR positive NOS1 neurons are mainly located in the PMv and also to much lesser degree, in the Arc and other brain sites, these results suggest an important role of hypothalamic NOSI neurons in body weight regulation.

72. - Hill JW, Elias CF, Fukuda M, et al. Direct insulin and leptin action on pro-opiomelanocortin neurons is required for normal glucose homeostasis and fertility. Cell Metab. 2010;11(4):28697. The authors deleted both insulin and leptin receptors in POMC neurons and found that mice lacking both receptors exhibited impaired glucose homeostasis and fertility. 
73. Cravo RM, Margatho LO, Osborne-Lawrence S, et al. Characterization of Kiss1 neurons using transgenic mouse models. Neuroscience. 2011;173:37-56.

74. Smith JT, Acohido BV, Clifton DK, Steiner RA. KiSS-1 neurones are direct targets for leptin in the ob/ob mouse. J Neuroendocrinol. 2006;18(4):298-303.

75. Castellano JM, Navarro VM, Fernandez-Fernandez R, et al. Expression of hypothalamic KiSS-1 system and rescue of defective gonadotropic responses by kisspeptin in streptozotocin-induced diabetic male rats. Diabetes. 2006;55(9):2602-10.

76. Mayer C, Boehm U. Female reproductive maturation in the absence of kisspeptin/GPR54 signaling. Nat Neurosci. 2011;14 (6):704-10.
77. •- Wu Q, Whiddon BB, Palmiter RD. Ablation of neurons expressing agouti-related protein, but not melanin concentrating hormone, in leptin-deficient mice restores metabolic functions and fertility. Proc Natl Acad Sci U S A. 2012;109(8):3155-60. This study investigates the effects of acute lesion of AgRP neurons on body weight and fertility in leptin-deficient ob/ob mice. Acute lesion of AgRP neurons rescues both body weight and fertility of ob/ob mice with moderate obesity but leads to death in either young, less obese or in old, severe obese ob/ob mice.

78. Myers Jr MG, Leibel RL, Seeley RJ, Schwartz MW. Obesity and leptin resistance: distinguishing cause from effect. Trends Endocrinol Metab. 2010;21(11):643-51. 